\title{
Na busca das origens da dramaturgia do movimento ${ }^{1}$
}

\author{
Prof. Dr. Milton de Andrade Leal $\mathrm{Jr}^{2} \quad$ Juarez José Nascimento \\ Nunes $^{3}$ \\ Participantes da pesquisa: Juarez José do Nascimento ${ }^{4}$, Bárbara \\ Biscaro $^{5}$, Samuel Romão ${ }^{6}$, Monica Siedler ${ }^{7}$
}

Palavras - chave: Composição, dramaturgia do movimento, dança-teatro.

Resumo: Este artigo procura, através de um breve estudo sobre as origens da dança moderna alemã, extrair o conceito dramaturgia do movimento como um modelo de composição dramática presente na atualidade cênica.

O conceito dramaturgia do movimento vem se tornando corriqueiro na atualidade cênica, no entanto, é fundamental afirmar que isto só é possível devido a um novo olhar direcionado ao texto dramático. "A definição de texto dramático é preciso não ser encarada de maneira estrita e tradicionalmente em cânones literários dramáticos “(Guinsburg, 2001; p. 13)

Precisa-se compreender que "dramaturgia do movimento" refere-se a um procedimento de composição não literário; encontrado numa zona cinzenta, um espaço de intersecção de duas expressões artísticas de onde é possível extraí-lo - a dança e o teatro.

Se, partirmos do sentido elementar de dramaturgia como composição de um drama, conclui-se que a dramaturgia do movimento é a composição de um drama através do movimento.

E, sendo assim, se, movimento no seu sentido físico é a variação espacial de um objeto ou ponto material no decorrer do tempo, a dramaturgia do movimento é a composição dramática de um deslocamento.

Para Pavis “dramaturgia é no seu sentido genérico a técnica da arte dramática que procura estabelecer os princípios de construção da obra, o que pressupõe um conjunto de regras especificamente teatrais." (1999, p. 113). A dramaturgia clássica examina exclusivamente o trabalho do autor

1 Artigo produzido a partir do Projeto de Pesquisa: Ritos da metamorfose corporal: entre a dança, a dramaturgia do corpo e a psicofísica do ator.

2 Professor do departamento de Artes Cênicas e Coordenador do Projeto

3 Bolsista de Iniciação Científica do Curso de Artes Cênicas - CEART-UDESC

4 Acadêmico Curso de Educação Artística - Habilitação em Artes Cênicas, CEART/UDESC, bolsista de iniciação científica do PROBIC/ UDESC.

5 Acadêmica do Curso de Educação Artística - Habilitação em Artes Cênicas, CEART/UDESC, bolsista de iniciação científica do PROBIC/ UDESC.

6 Participante da Pesquisa e Acadêmico Curso de Educação Artística - Habilitação em Artes Cênicas, CEART/UDESC.

7 Participante da Pesquisa Acadêmica do Programa de Pós-graduação em Teatro, CEART/UDESC. 
e a estrutura narrativa da obra, enquanto que a partir de Brecht esta noção abrange o texto de origem e os meios da encenação. Pavis afirma ainda: que a dramaturgia enquanto atividade do dramaturgo instala os materiais textuais e cênicos, destaca os significados complexos do texto ao escolher uma interpretação particular orientando o espetáculo num sentido escolhido". (1999, p. 113)

Enquanto realização de uma equipe, do encenador ao ator, a dramaturgia designa um conjunto de escolhas estéticas e ideológicas. Em seu sentido mais atual, a dramaturgia ultrapassa o estudo do texto dramático articulando texto e encenação permitindo espaço a outras abordagens como da dramaturgia do movimento.

A dramaturgia do movimento, enquanto composição de um drama, segue um conjunto de regras ampliando a noção clássica de dramaturgia abrangendo meios cênicos que vão além dos textuais.

Porém, se temos abdicado o trabalho clássico do dramaturgo enquanto autor, nesta zona cinzenta, da dança-teatro, onde encontramos a dramaturgia do movimento, teremos o trabalho do dramaturgo diluído entre o ator-dançarino e o coreógrafo-encenador.

Conclui-se, assim, que a dramaturgia do movimento aqui abordada é uma decorrência histórica da fusão entre a dança, o teatro e a arte do movimento, e enquanto elemento cênico é uma forma não literária de composição dramática que utiliza as leis do drama e as leis do movimento como elementos de linguagem. Decorre daí a importância de se estudar as origens da dança-teatro no início do século XX.

\title{
Consoante Patrice Pavis:
}

\begin{abstract}
Dança-teatro (expressão traduzida do alemão Tanztheater) é conhecida, sobretudo através de P. BAUSCH, porém tem sua origem no Folkwang Tanz-Studio, criado em 1928 por K. JOOSS que foi professor de BAUSCH e proveio ele próprio da Ansdruckstanz, a dança expressionista alemã. A esta corrente da criação coreográfica contemporânea pertencem igualmente JOHANN KRENIK e seu teatro coreográfico, R. HOFFMANN e G. BOHNER, na França M. MARIN, os quais apesar de não utilizarem este termo, são conhecidos como coreógrafos abertos à teatralidade e favoráveis à descompartimentação das artes cênicas.” (PAVIS , 1999; p. 83).
\end{abstract}

A dança-teatro surge como reação aos formalismos da dança moderna, ultrapassando as oposições como: corpo e linguagem, movimento puro e fala, pesquisa formal e realismo; e objetiva a coexistência entre "cinese" e "mimese". Além disso, a dança-teatro recoloca o dilema da dança entre o movimento puro e a pantomima com seu gosto por uma história simples, procurando produzir o efeito do teatro ( Pavis, 1999, pp. 83 e 84). 
O termo dança-teatro, segundo Isa Partsh Bérgsohn ${ }^{8}$, nos leva aos anos 20 na Alemanha quando Rudolf Laban, distanciando-se da dança como expressão de sentimentos subjetivos, publica em 1920 a sistematização do seu pensamento sobre o movimento da dança no livro Die Welt des Tänzers (O Mundo do Dançarino). Com a Companhia de Dança de Hamburgo, Laban provou suas teorias na prática em torno das leis fundamentais do movimento humano, trabalhou para representar no palco sua nova forma de dança (dança moderna), distinguiu movimento coral e dança-teatro.

O movimento coral servia para dar uma experiência ao leigo, enquanto que na dança teatro dançarinos profissionais treinados apresentavam a forma de arte da dança.

Diferenciava as danças de acordo com sua estrutura como orquestra, dança coral ou câmara, incluindo danças menores como a sonata e a canção. (Partshh-Bergsohn, 1988)

Com a distinção entre movimento coral e dança-teatro abre-se o caminho a ser seguido por dois alunos de Rudolf Laban: Mary Wigman e Kurt Joos. Wigman colaboradora de Laban dançava às vezes sem acompanhamento em busca de sentir o ritmo corporal e, procurando seu próprio caminho, foi mais específica sobre sua concepção de dança teatro. Segundo Partsch-Bergshon, para Wigman "a humanidade é o tema básico de uma ilimitada e eternamente significativa seqüência de variações. Suas danças eram abstratas, claras em forma e expressionistas em seu uso de distorção, algumas realizadas em completo silêncio." (Partsh-Bergsohn, 1988).

Após ter passado por uma experiência difícil com a montagem de Totenmal (Monumento para os mortos, coreografia de 1930, sem música para o poema de Alberto Talhof), Wigman reavaliou se o grau de abstração empregado neste trabalho ainda estava no campo da dança.; objetivou o renascimento contemporâneo do teatro grego antigo, criou ritmos espaciais através de simples locomoções unificadas em grandes ações de coral e colaborou com diretores alemães de destaque. Em uma de suas obras escreveu:

\footnotetext{
"A irredutível exigência da dança coral no seu criador, o coreógrafo é a simplicidade, e uma vez mais a simplicidade na organização do espaço, no seu conteúdo rítmico, nas nuances dinâmicas do caminho da atitude corporal e do gesto". (Wigman, cit. in Partsch-Bergsohn, 1988)
}

8 Isa Partsch-Bergsohn: Professora da Universidade do Arizona, Tucson, autora do livro Modern Dance in Germany and the United States (A Dança Moderna na Alemanha e nos Estados Unidos), Hardwood Publisher, 1994; ensinou para a Folkwang Schule, em Essen (Alemanha), por sete anos. 
Wigman contribuiu de forma relevante dando passo importantes na direção de definir a dança teatro do início do século XX, como também atingiu um balanço extraordinário das diferentes formas de arte.

Kurt Jooss, outro aluno de Laban entendia a dança-teatro como uma ação grupal dramática. Conheceu Laban nos anos 20, estudou com este, foi membro da Cia. de Hamburgo e em 1925 tornou-se diretor de dança no teatro Münster, criando aí sua primeira coreografia; migra para Essen onde se torna co-fundador e diretor de dança da Folkwang Schule, seguindo os ideais de Laban combinando música, dança e educação da fala.

Do ponto de vista pedagógico e coreográfico, formou dançarinos de acordo sua concepção de dança-teatro; no espetáculo Mesa Verde (1932) levou a fundo a questão do conteúdo. Para Jooss o conteúdo concreto em um trabalho artístico ganha significado. Considerando o conceito de drama em relação à palavra, Jooss argumentou que a eliminação do discurso verbal enfatiza o gesto que será intensificado.

Muda com sua companhia, em 1933, para Inglaterra onde estabelece uma escola, esteve também na Holanda e Suécia, viajando nos anos 30 por toda Europa, onde segundo Isa Partsh Bérgson, o público viu o estilo Jooss como "uma forma modernizada de balé".

Outro expoente da dança-teatro, Pina Bausch, ainda viva, graduou-se em 1959 na Folkwang Hochschule de Essen, estuda na Julliard, escola de música em New York, onde trabalha com Antony Tudor - coreógrafo do balé britânico que criava seus personagens mostrando suas motivações psicológicas através de gestos expressivos.

Nesta época em Nova York, havia uma forte reação à formalidade técnica da dança moderna coma a vanguarda buscando alternativas e experimentando danças e estilos. Cansados de heroísmos segmentos da dança ficavam os movimentos de pedestres e observando relações básicas do ser humano em seu cotidiano.

Bausch esteve receptiva a questões do meio ambiente, direitos civis, feminismo, minorias, preocupações antinucleares expressos em todas as artes dos anos 60 e em novas maneiras de produzir significados.

Em 1962, retorna para Folkwang Hochschule na Alemanha, recebendo de Jooss a posição de solista líder no recente formado Folkwang Ballet e leciona técnicas de dança moderna. Partsh-Bergshon considera que Baush é consciente da dinâmica do espaço, refinou gestos e fraseados e aguçou sua observação aprendendo articular movimentos de dança e o uso orquestral da companhia.

Com o histórico acima apresentado, em relação às primeiras definições apontadas no início deste artigo, podemos observar que: (a) se o teatro clássico e mesmo o moderno mantém como um 
de seus elementos essenciais o texto dramático, compreendido em seu sentido canônico literário, a dança-teatro o substitui pelo movimento. É através do movimento que a dança-teatro, herança da dança moderna, compõe seu drama possibilitando-nos nomear esta composição de dramaturgia do movimento; (b) a dramaturgia do movimento é resultante histórico de um distanciamento da "dança como expressão de sentimentos subjetivos" em Laban, tornando-se uma "ação grupal dramática, técnica de coreografia dramática" em Jooss.

\section{REFERÊNCIAS}

GUINSBURG, Jacó. Da Cena em Cena. São Paulo: Perspectiva, 2001.

PAVIS, Patrice. Dicionário de Teatro. São Paulo: Perspectiva, 1999.

PARTSCH-BERGSOHN, Isa. "DanceTheatre from Rudolph Laban to Pina Bausch" in Dance Theatre Journal, vol 6, no. 02 outono de 1988, pp. 37 a 39. Tradução de Ciane Fernandes (Universidade Federal da Bahia) A Dança-Teatro de Rudolf Laban a Pina Bausch - Tradução Ciane Fernandes. Site: http://www.revista.art.br ; Acessado em 02/07/07. 